\title{
The challenge of costly drugs
}

\section{Charles Denaro \\ Director \\ Department of Internal \\ Medicine and Aged Care \\ Royal Brisbane and \\ Women's Hospital \\ Associate professor of \\ Medicine \\ University of Queensland \\ Jennifer Martin \\ Chair of Clinical \\ Pharmacology \\ University of Newcastle \\ Senior staff specialist \\ Calvary Mater Newcastle \\ Hospital}

\section{Keywords}

cost-effectiveness of drugs, hepatitis C, Pharmaceutical Benefits Scheme

Aust Prescr 2016;39:72-4 http://dx.doi.org/10.18773/ austprescr.2016.037
From June 2005 to June 2014 the annual cost of the Pharmaceutical Benefits Scheme (PBS) rose from $\$ 6$ billion to $\$ 9.15$ billion. That is an increase of $52 \%$ or a growth rate of nearly $6 \%$ each year. At the same time the Highly Specialised Drugs and Section 100 programs of the PBS, which subsidise the most expensive drugs, increased by $200 \%$ or nearly $23 \%$ each year. ${ }^{1}$ This growth has been largely driven by the arrival of expensive biological therapies, antiviral therapies for HIV and hepatitis C, and a variety of small molecules used to inhibit growth in subsets of various cancers. In Australia, enzyme replacement therapy for lysosomal storage diseases, funded by the separate Life Saving Drugs Program, can cost more than $\$ 200000$ per person, per year, for life. However, this therapy is not funded in New Zealand for Fabry disease, the commonest lysosomal storage disease.

In 2011 New Zealand paid less than half what Australia spent on medications per capita. This has been achieved by having a capped budget and competitive tendering. ${ }^{2}$ In Australia there is a need to consider the fourth arm of the National Medicines Policy which aims to provide a consistent and supportive environment for the industry. ${ }^{3}$

The challenges are many, including knowing whether taxpayers are receiving value for money, funding treatments for our expanding ageing population, predicting long-term outcomes and cost-effectiveness for highly expensive medicines with inadequate long-term trial data. There are also the challenges in justifying extremely costly drugs for a few patients with a rare disease, and finding the funding while not reallocating resources from other areas of health care.

Many trials of costly drugs do not provide the information required to make a considered and accurate judgement of their value, particularly if registration or funding is based on phase II or observational data in small numbers of patients. Short-term surrogate end points for lifelong or lifethreatening diseases also make the estimates of costeffectiveness imprecise. For example, many expensive cancer therapies measure time to progression, but cannot quantify overall survival differences as patients in the control arm are often allowed to cross over to the active arm if the cancer progresses. ${ }^{4}$ Treatments for rare diseases are a great development, but are also difficult to assess because the trials cannot recruit enough patients for long enough to show clear clinical end points. What is the true return on investment? What is lost if a new costly drug is approved? Can one make a considered value judgement if the median survival benefit is a couple of months?

A measure used in economic analysis is the qualityadjusted life-year (QALY). One QALY is one year of perfect health. QALYs can standardise the quality and quantity of life across diseases and populations. However they also have problems. ${ }^{5}$ They are a relatively generic measure seen by some clinicians as lacking the specificity that is required in daily practice. In addition, the weighting system used to compute the QALY is most often calibrated in terms of social preferences sometimes derived in healthy populations rather than patients. Thus there is a reasonably valid belief that the value attached to quality of life may be determined by economists making deductions on assumptions that are not relevant to seriously ill patients.

Another challenge is to decide which patients will need treatment. Sofosbuvir is a new efficacious antiviral treatment for hepatitis $\mathrm{C}$. However, it is very expensive, originally costing about US\$84 000 for a 12-week course. Is it cost-effective to treat everyone when only a small percentage of patients with persistent hepatitis $\mathrm{C}$ infection will develop cirrhosis or hepatocellular cancer? The numbers in different studies vary - one cohort study in Germany followed 1980 women for 25 years. Overt cirrhosis developed in $0.5 \%$ and advanced fibrosis developed in $1.5 \%$. Only one patient developed hepatocellular carcinoma. ${ }^{6}$ After 35 years cirrhosis had only developed in $14 \%$ who remained viraemic. Despite these concerns the company marketing sofosbuvir recouped its initial outlay of US\$11 billion (to buy this drug from a biotechnology company) in its first year of sales. ${ }^{7}$ While there may be other benefits that are not yet studied or quantified, for example reduced infection risk and reduced general inflammatory symptoms such as fatigue, they come at a high price. Is it acceptable to delay treatment until the patent expires and generics become available? The benefits in terms of cost savings, and therefore the ability to make the drug available to wider populations as the evidence becomes available, could also be measurable.

The pharmaceutical industry is among the most profitable industries in the world. ${ }^{7}$ While innovation and entrepreneurship must be encouraged, it is impossible to know exactly the cost to develop and bring a new drug to the market. Many breakthroughs have come from government-funded or universityfunded basic research.7 'Big pharma' then brings the product to market. In fact pharmaceutical companies' 
spending on sales and marketing dwarfs their investment in research and development outlays.

The way drugs are registered can influence their cost. Ranibizumab is approved for neovascular macular degeneration. However, it costs 40 times more than bevacizumab which is equally efficacious, but not approved for this indication. ${ }^{8}$

If only one supplier pays the Therapeutic Goods Administration (TGA) to evaluate an old, offpatent drug, it can charge a fortune if the drug is approved. For example, in 2003 thalidomide cost around $\$ 6$ per capsule, but now costs approximately $\$ 30$ per capsule.

The Pharmaceutical Benefits Advisory Committee (PBAC) has access to independent pharmacoeconomic expertise to assess submissions for including a drug on the PBS. However, many costly drugs only have a role in Australian public hospitals, and state governments do not fund comprehensive pharmacoeconomic assessments or even clinical pharmacologists for formulary decisions. Deciding whether to add a drug to a hospital formulary is thus problematic, especially as the funding must come out of a capped hospital budget, and relativity assessments such as QALYs are unable to guide decisions. Decisions across Australia are therefore haphazard and access to drugs may be determined by where the patient lives and the quality of the assessment by hospital formulary committees.

Drug companies are profit driven, while Australians are looking for the best value for money. What is the way forward?

Patents for some expensive biological therapies have expired or will expire in the near future. Biosimilars are mimic molecules of these therapies and potentially offer significant cost savings. However, they are not identical and require careful evaluation before marketing. Guidelines for biosimilar products have been produced. ${ }^{9}$

There is often much uncertainty about value for money, so post-marketing surveillance is required to assess important clinical outcomes. Unfortunately drug companies are less likely to fund expensive definitive trials once the drug is marketed. Funding for independent assessment is required. Drugs that do not realise their initial promise should be considered for removal from the PBS. Cinacalcet was removed from the PBS after reassessment of its cost-effectiveness. ${ }^{10}$

The TGA and the PBS charge applicants significant assessment fees and the legal liability for the drug once marketed in Australia remains with the applicant. The TGA and PBS should waive these fees in special circumstances to allow submissions from learned societies. Such circumstances should be limited to older drugs where the indication for their use is cost-effective compared to other drugs and where robust evidence for efficacy and safety exists. This would expedite the listing of new indications for current drugs (currently used off label) and have older, off-patent drugs listed and available. In this setting the liability incurred should rest with the Commonwealth. This would allow, for example, bevacizumab to be used for neovascular macular degeneration and diabetic retinopathy.

The cost of medicines may be influenced by factors such as international trade agreements, for example the Trans-Pacific Partnership." There may need to be safeguards for patients and taxpayers if such agreements affect access to affordable drugs or delay the availability of generic or biosimilar drugs. ${ }^{12}$

An electronic national formulary for all Australian hospitals could be beneficial. It could be funded by the Commonwealth and updated regularly by a national formulary committee similar in structure to the PBAC. This would improve decision making and allow uniform access to efficacious and cost-effective drugs for all Australians irrespective of where they live. $<$

Conflict of interest: Charles Denaro is the Chair of the Queensland Health Medicines Advisory Committee. He currently serves on the Fabry Disease Advisory Boards for Genzyme and Shire, and was previously on the advisory boards of CSL and Menarini. He has received honoraria for speaking by Mundi Pharma and Shire, and was involved in a number of phase III trials for new oral anticoagulants - Bayer, Pfizer and Boehringer Ingelheim - and received sponsorship to attend conferences by Novartis, Sanofi, MSD, Vifor Pharma, Menarini and Astra Zeneca.

Conflict of interest: Jennifer Martin has been a member of the Pharmaceutical Benefits Advisory Committee and Queensland Health Medicines Advisory Committee. She is currently an Advisor to the Ministry of Health (New Zealand) Pharmacology and Therapeutic Advisory Committee and an external evaluator for the Therapeutic Goods Administration.

\section{REFERENCES}

1. The Pharmaceutical Benefits Scheme. PBS statistics. Canberra: Department of Health; 2015. www.pbs.gov.au/ info/browse/statistics [cited 2016 May 1]

2. Babar Z, Vitry A. Differences in Australian and New Zealand medicines funding policies. Aust Prescr 2014;37:150-1. http://dx.doi.org/10.18773/austprescr.2014.059
3. National Medicines Policy 2000. Canberra: Department of Health and Ageing; 1999. www.health.gov.au/internet/main/ publishing.nsf/Content/B2FFBF72029EEAC8CA257B F0001BAF3F/\$File/NMP2000.pdf [cited 2016 May 1] 
4. The Pharmaceutical Benefits Scheme. Crizotinib; 200 mg capsule, 60 and 250 mg capsule, 60; Xalkori. Canberra: Department of Health; 2015. www.pbs.gov.au/info/industry/ listing/elements/pbac-meetings/psd/2014-11/crizotinibpsd-11-2014 [cited 2016 May 1]

5. Kind P, Lafata JE, Matuszewski K, Raisch D. The use of QALYS in clinical and patient decision-making: issues and prospects. Value Health 2009;12 Suppl 1:S27-S30. http://dx.doi.org/ 10.1111/j.1524-4733.2009.00519.x

6. Wiese M, Grüngreiff K, Güthoff W, Lafrenz M, Oesen U, Porst H; East German Hepatitis C Study Group. Outcome in a hepatitis $C$ (genotype $1 b$ ) single source outbreak in Germany--a 25-year multicenter study. J Hepatol 2005;43:590-8. http://dx.doi.org/10.1016/j.jhep.2005.04.007

7. Avorn J. The $\$ 2.6$ billion pill--methodologic and policy considerations. N Engl J Med 2015;372:1877-9. http://dx.doi.org/10.1056/NEJMp1500848

8. Harvey KJ, Day RO, Campbell WG, Lipworth W. Saving money on the PBS: ranibizumab or bevacizumab for neovascular macular degeneration? Med J Aust 2011;194:567-8.
9. Council of Australian Therapeutic Advisory Groups. Overseeing biosimilar use: guiding principles for the governance of biological and biosimilar medicines in Australian hospitals. Sydney: CATAG; 2015 www.catag.org.au/resources [cited 2016 May 1]

10. Sensipar (cinacalcet) PBS listing to be deleted. NPS RADAR 2015 April. www.nps.org.au/publications/healthprofessional/nps-radar/2015/april-2015/brief-item-sensipa [cited 2016 May 1]

11. Trans-Pacific Partnership Agreement. Canberra: Department of Foreign Affairs and Trade; 2016. http://dfat.gov.au/ trade/agreements/tpp/Pages/trans-pacific-partnershipagreement-tpp.aspx [cited 2016 May 1]

12. Thow AM, Gleeson DH, Friel S. What doctors should know about the Trans-Pacific Partnership Agreement. Med J Aust 2015;202:165-6. http://dx.doi.org/10.5694/mja14.01714

\section{Letters to the Editor}

\section{Metformin and patients on dialysis}

Aust Prescr 2016;39:74-5

http://dx.doi.org/10.18773/austprescr.2016.041

I enjoyed reading the concise, well-referenced summary on prescribing for patients on dialysis.' However, the statement 'Metformin is contraindicated due to the risk of lactic acidosis' is not referenced and is perhaps not supported by the available evidence.

A Cochrane review on the risk of fatal and nonfatal lactic acidosis with metformin use in type 2 diabetes concluded that there is no evidence at present that metformin is associated with an increased risk for lactic acidosis when prescribed under the study conditions. $^{2}$ The authors commented that of the 334 prospective studies, 143 (53\%) allowed for the inclusion of renal insufficiency, following 37360 patient-years of metformin use. One trial in the review questioned the standard contraindications by studying 393 patients, all with at least one contraindication to metformin use, and found no cases of lactic acidosis over four years. ${ }^{3}$ All of the patients had renal insufficiency, with mean plasma creatinine concentrations of $1.5-2.5 \mathrm{mg} / \mathrm{dL}$ (mean $1.8 \mathrm{mg} / \mathrm{dL}$ ).

A review of metformin in chronic kidney disease nicely summarises the issue. ${ }^{4}$ It cites two small studies of metformin use in dialysis patients and recommends $250 \mathrm{mg}$ daily for peritoneal dialysis patients and $500 \mathrm{mg}$ after each dialysis session for those receiving haemodialysis.

Metformin is renally excreted and in overdose has been seen to cause lactic acidosis without other contributory comorbidity. While there are grounds for caution in patients on dialysis, an increased risk of lactic acidosis has not been specifically established. Many renal physicians choose to administer metformin in reduced doses to selected patients with end-stage renal disease because of its proven efficacy in the management of overweight patients with type 2 diabetes.

Stephen Richards

Renal physician

Perth

\section{REFERENCES}

1. Smyth B, Jones C, Saunders J. Prescribing for patients on dialysis. Aust Prescr 2016:39:21-4. http://dx.doi.org/ 10.18773/austprescr.2016.008

2. Salpeter SR, Greyber E, Pasternak GA, Salpeter EE. Risk of fatal and nonfatal lactic acidosis with metformin use in type 2 diabetes mellitus. Cochrane Database Syst Rev 2010:CD002967. http://dx.doi.org/10.1002/14651858.CD002967.pub4

3. Rachmani R, Slavachevski I, Levi Z, Zadok B, Kedar Y Ravid M. Metformin in patients with type 2 diabetes mellitus: reconsideration of traditional contraindications. Eur J Intern Med 2002;13:428-33. http://dx.doi.org/10.1016/ S0953-6205(02)00131-0

4. Heaf J. Metformin in chronic kidney disease: time for a rethink. Perit Dial Int 2014;34:353-7. http://dx.doi.org/ $10.3747 /$ pdi.2013.00344 